\title{
Extraction of Ascorbic Acid from Acerolas (Malpighia punicifolia L.)
}

\author{
R. Santini, Jr., and J. Nevarez ${ }^{1}$
}

\section{INTRODUCTION}

Asenjo and Freire de Guzmán $(1)^{2}$ have shown that the acerola is the best natural source of ascorbic acid. The content of ascorbic acid in the fruit ranges from 1.03 to $2.70 \mathrm{gm}$. per $100 \mathrm{gm}$. of edible pulp. The results obtained by Asenjo were confirmed by Vieta de Ruiz, et al., (2) in Cuba, and by Mustard (3) in Florida. Working along the same line, values which correspond with those reported by Asenjo have been obtained in the Chemistry Department of the Agricultural Experiment Station of the University of Puerto Rico.

Experiments carried out at this Station have shown that the ascorbic acid content of the acerola juice suffers little change when the juice is flash-pasteurized and canned (4). During storage for 1 year at $45^{\circ} \mathrm{F}$., about 82 percent of the ascorbic acid content of the juice is retained, but when stored at room temperature only about 50 percent is retained (5).

The high ascorbic acid content of the acerola juice makes its use desirable as a dietary supplement in ascorbic acid deficiencies. However, the use of the acerola juice is at present limited by the darkening of the juice and the concurrent loss of flavor that takes place on pasteurization and canning.

\section{LITERATURE REVIEW AND OBJECTIVES}

Various methods have been used for the isolation of ascorbic acid from plant extracts. These have generally involved organic-solvent fractionation, heavy-metal-salt precipitation, or both. Attempts to apply these procedures in the laboratory indicated that the methods were too indirect and inefficient to have commercial possibilities in competition with synthetic ascorbic acid.

Asenjo, et al., used the lead-salt precipitation method of Banga and SzentGyörgyi (6) to confirm the presence of ascorbic acid in the acerola. The method is very efficient, but requires the use of lead salts, which, besides being very expensive, are very poisonous. A more recent method suggested is the chromatographic method of Sastri and Sivaramakrishan (7) which

1 Associate Chemist and Analyst, respectively, of the Agricultural Experiment Station, University of Puerto Rico, Río Piedras, P. R. The author wishes to express his thanks to Miss N. Nadal for her assistance in the analyses performed.

${ }^{2}$ Numbers in parentheses refer to Literature Cited, p. 189. 
uses activated magnesia as the absorbent. Some preliminary work was done using this method for the acerola, but the results were very poor.

A third method found in the literature is that of Mottern and Buck (8). They developed a process for the recovery of ascorbic acid from citrus and other natural products by the use of ion-exchange resins. This method was subsequently patented in 1944, and is under license to the Permutit Co. However, we were unable to obtain the ascorbic acid in crystalline form by using this method.

Mottern and Buck recommend a 10-percent sulfuric acid solution to elute the ascorbic acid from the column. When we tried to eliminate the sulfuric acid in excess by precipitation with barium chloride and then concentrate the filtrate to 10 percent of its original volume, almost all the ascorbic acid was lost. In a letter that we received from A. B. Mindler, Special Applications Department of the Permutit Co., regarding the crystallization of the ascorbic acid, the following information was given:

It is true that U. S. Patent $2,443,583$ is under license to the Permutit Co. but I do not know whether we can aid you very much in your work of developing a process employing ion-exchange for ascorbic acid recovery since the problem of ascorbic acid crystallization has not been solved for the recovery of ascorbic acid from the elution solutions.

Klose, et al., (9) at the Western Utilization Research Branch, USDA, developed a more direct method for the isolation of ascorbic acid from green walnut hulls. Their experimental procedure may be summarized as follows: Extraction of the vitamin from the hulls using a dilute $\mathrm{SO}_{2}$ solution, purification of the extracts by absorption on, and the elution from anion-exchange resins; and crystallization from the concentrated, decolorized eluate.

This method worked very well, but it could not be applied commercially because there is only one crop of the walnuts during the year and because the process of extraction of the ascorbic acid from the hulls with dilute $\mathrm{SO}_{2}$ solution is very expensive. However, since the acerola yields from two to four crops during the year, since these fruits have a higher ascorbic acid content than the green walnut hulls and further, since the ascorbic acid in the acerolas is found dissolved in the juice, making the cost of the extraction of the ascorbic acid from the fruit very small as compared to the procedure required for extracting the acid from the green walnut hulls, it seemed as if ion-exchange might be used commercially to isolate the ascorbic acid from the juice of pressed acerolas.

\section{EXPERIMENTAL PROCEDURE}

The procedure developed by the authors for recovering the ascorbic acid from acerola juice is as follows: The juice is passed through a cation- 
exchanger in the acid cycle until the $\mathrm{pH}$ drops to less than 2 . Then it is passed through an anion-exchange resin in the alkaline cycle (this was preferred to the method used at the Western Utilization Research Branch of putting an anion-exchanger into the acid cycle). The anion-exchange columns are washed with distilled water and the elution is carried out using a dilute solution of $\mathrm{HCl}$. The eluate is then decolorized, using Norit A, and is concentrated to $65^{\circ} \mathrm{Brix}$. The concentrate is left at $0^{\circ} \mathrm{C}$. for 2 days and the crystals are then washed with $\mathrm{N}$-butyl alcohol and dried.

The cation-exchanger used so far has been Amberlite IR-120 and the anion-exchanger has been Amberlite IR-4B. These have proved to be very efficient. However, more research remains to be done with different resins to find the anion-exchanger which has the greatest capacity for the ascorbic acid.

A $0.5 \mathrm{~N} \mathrm{HCl}$ solution was used for the elution. Other concentrations of $\mathrm{HCl}$ were tried, and this seemed to be satisfactory. Additional work in this connection should yield information as to the most suitable and economic concentration.

\section{RESULTS}

In the elution procedure an average of about 77 percent of the adsorbed ascorbic acid can be recovered from the column. Table 1 shows the recovery obtained in several experiments conducted.

Although the percentage recovery of the ascorbic acid from the anionexchange column is very high, more research will be required to obtain higher yields. This work will include such factors as the time the acid is in contact with the resin, the volume required for as complete an elution as possible, the size of the columns, and the substitution of other acids for $\mathrm{HCl}$.

TABLE 1.-Recovery of ascorbic acid from the anion-exchanger by elution with $0.5 \mathrm{~N} \mathrm{HCl}$

\begin{tabular}{c|c|c|c}
\hline Sample No. & Ascorbic acid adsorbed & Ascorbic acid eluted & Recovery of ascorbic acid \\
\cline { 2 - 3 } 1 & Grams & Grams & Percen! \\
63.8 & 50.8 & 79.6 \\
3 & 62.0 & 44.2 & 71.3 \\
4. & 133.0 & 95.0 & 71.4 \\
5 & 180.0 & 140.0 & 77.8 \\
6 & 180.0 & 108.0 & 60.0 \\
7 & 191.0 & 147.2 & 77.0 \\
8 & 161.0 & 137.9 & 85.7 \\
& 198.6 & 190.3 & 96.0 \\
\hline
\end{tabular}


TABLE 2.-Concentration of ascorbic acid, by volume, during the elution procedure in 7 experiments

\begin{tabular}{l|l|l|l|l|l|l|l|l|l|l|}
\hline Eluate No. & $\begin{array}{c}\text { Normality } \\
\text { of acid }\end{array}$ & $\begin{array}{l}\text { Volume of } \\
\text { acid used }\end{array}$ & \multicolumn{6}{|c}{ Amount of ascorbic acid in eluate- } \\
\cline { 3 - 7 } & 1 & 2 & 3 & 4 & 5 & 6 & 7 \\
\hline
\end{tabular}

Experiment 1

\begin{tabular}{r|r|r|r|r|r|r|r|r|r}
\hline & & Milliliters & Grams & Grams & Grams & Grams & Grams & Grams & Grams \\
2 & 0.1 & 500 & 0.11 & 0.11 & 0.07 & 0.29 & 0.02 & & \\
3 & .1 & 500 & 1.39 & 2.19 & .95 & 1.03 & .87 & & \\
4 & .1 & 500 & 1.18 & 1.16 & .78 & .89 & 1.54 & & \\
5 & .1 & 500 & 1.69 & .62 & 1.77 & .87 & .88 & & \\
6 & .1 & 500 & 1.09 & 1.34 & .45 & .70 & .47 & & \\
7 & .1 & 500 & .49 & .85 & .33 & .71 & .45 & & \\
\hline
\end{tabular}

Experiment 2

\begin{tabular}{l|r|r|r|r|r|r|r|r|r}
\hline 1 & 0.2 & 500 & 4.49 & 0 & 0 & 0 & 0 & & \\
2 & .2 & 500 & 6.76 & 5.92 & 6.56 & 2.98 & 3.85 & & \\
3 & .2 & 500 & 5.23 & 2.71 & 2.94 & 1.22 & 2.51 & & \\
4 & .2 & 500 & .75 & .95 & .50 & .64 & .70 & & \\
\hline \multicolumn{7}{c}{ Experiment 3 } \\
\hline 1 & 0.5 & 500 & 3.41 & 3.23 & 0.28 & 0.28 & 0.38 & 843 & \\
2 & .5 & 500 & 6.72 & 5.18 & 2.71 & 2.75 & 3.32 & 3.25 & \\
3 & .5 & 500 & 5.46 & 7.36 & 9.52 & 9.39 & 7.59 & 8.09 & \\
4 & .5 & 500 & 1.53 & 1.12 & 2.03 & 2.63 & 1.58 & 1.73 & \\
5 & .5 & 500 & 0 & 0 & 0 & 0 & 0 & 1.85 & \\
\hline
\end{tabular}

Experiment 4

\begin{tabular}{l|r|r|r|r|r|r|r|r|r}
\hline 1 & 0.5 & 500 & 0 & 0 & 1.87 & 1.98 & 1.08 & 0 \\
2 & .5 & 1,000 & 9.66 & 10.09 & 5.82 & 9.31 & 9.57 & 8.22 & \\
3 & .5 & 1,000 & 8.09 & 7.00 & 2.08 & 4.70 & 7.57 & 10.04 & \\
4 & .5 & 500 & 1.96 & 0 & 0 & .10 & .35 & 4.70 & \\
\hline
\end{tabular}

Experiment 5

\begin{tabular}{r|r|r|r|r|r|r|r|r|r}
\hline 1 & 0.5 & 1,000 & 4.98 & 5.58 & 4.76 & 6.43 & 5.84 & 3.58 & \\
2 & .5 & 1,000 & 11.89 & 10.37 & 10.35 & 5.47 & 9.97 & 11.03 & \\
3 & .5 & 500 & 3.30 & 1.85 & 1.60 & .44 & 1.74 & 4.22 & \\
\hline \multicolumn{10}{c}{ Experiment 6} \\
\hline 1 & 0.5 & 1,000 & 4.65 & 12.54 & 5.46 & 2.90 & 6.82 & 6.42 & 8.95 \\
2 & .5 & 1,000 & 13.37 & 9.77 & 11.61 & 15.4 & 9.32 & 9.24 & 9.78 \\
3 & .5 & 1,000 & 2.64 & 1.32 & 2.16 & 3.0 & 1.05 & .97 & 4.27 \\
\hline \multicolumn{10}{l}{ Experiment 7} \\
\hline 1
\end{tabular}


The concentration of ascorbic acid by volume in the elution is summarized in table 2, which shows that the ascorbic acid content rises to a maximum in the second or third elution and then drops.

Klose, et al., recommended that the eluate be concentrated in vacuo to about 40-percent solids, decolorized, and then further concentrated to 70-percent solids. We have found that it is better to decolorize the eluate before concentrating in vacuo, because with a dilute solution the loss of ascorbic acid during decoloration is reduced to a minimum, and the loss which occurs in the handling of the sample (taking the sample out of the evaporator, decolorizing, and returning it to the evaporator) is eliminated.

Crystallization occurred after standing at $0^{\circ} \mathrm{C}$. for 2 days. The crystals were washed with $\mathrm{N}$-butyl alcohol and dried, but when this alcohol had not purified the ascorbic acid completely, a recrystallization was made from ethyl alcohol. The vitamin. was identified by determination of its melting point $\left(190-192^{\circ} \mathrm{C}\right.$.), by mixed melting-point determination with synthetic ascorbic acid, by titration with 1,2 dichlorophenol indophenol $(10)$, and by determination of its specific rotation $\left(+21.3^{\circ}\right)$.

In one of our experiments a decolorized eluate containing $146 \mathrm{gm}$. of ascorbic acid was concentrated to $65^{\circ} \mathrm{Brix}$ and allowed to crystallize at $0^{\circ} \mathrm{C}$. for 2 days. The crystals were washed with $\mathrm{N}$-butyl alcohol and then recrystallized from ethanol and $85 \mathrm{gm}$. of pure ascorbic acid were obtained. Since about $20 \mathrm{gm}$. remained in the low-temperature evaporator and 30 $\mathrm{gm}$. remained in the mother liquor, the yield for a continuous process would be 88 percent.

This process could be worked continuously with very high yields because: 1 , The resins could be regenerated and used for a very long time; 2 , the percentage of recovery of ascorbic acid from the column was very high; 3 , the amount lost during decolorization was negligible; 4 , the amount lost in the concentration operation was only that left as a film on the walls of the evaporator and, in a continuous process this would be negligible; 5 , the amount of ascorbic acid which stayed in the mother solution after crystallization could be added to fresh juice which had been passed through the cation-exchangers and again subjected to the process, hence the amount remaining in the mother solution was always constant and, in a continuous process, it would be negligible as well.

\section{SUMMARY}

The acerola is considered to be the best natural source of ascorbic acid, it yields from two to four crops during the year, and the ascorbic acid is found dissolved in the juice.

Therefore, a method which was used previously for separating and crystallizing the ascorbic acid present in the green walnut hulls, but which 
could not be applied commercially thereto, has been modified and applied to the acerola.

The method involved the use of ion-exchange resins. A cation-exchange resin was used to lower the $\mathrm{pH}$ below 2 and an anion-exchange resin to absorb the ascorbic acid. This acid was eluted from an anion-exchange column with a dilute hydrochloric acid solution.

On a laboratory scale the yields obtained were relatively high and in a continuous commercial process the yield should be about 88 percent.

\section{RESUMEN}

La acerola se considera como la mejor fuente de ácido ascórbico. Se obtienen de dos a cuatro cosechos de esta fruta durante el año y el ácido ascórbico se encuentra disuelto en el jugo.

Un método que se usó originalmente para extraer y cristalizar el ácido ascórbico de la cáscara de las nueces verdes, pero que no se pudo usar comercialmente, ha sido modificado y aplicado a la acerola.

El método conlleva el uso de resinas que intercambian iones. Una resina que intercambia cationes se usa para bajar el $\mathrm{pH}$ del jugo de acerola a $2 \mathrm{y}$ una resina que intercambia aniones se usa para absorber el ácido ascórbico. Este se extrae de la resina con una solución diluída de ácido clorhídrico.

El rendimiento obtenido en escala de laboratorio fué alto y se espera que en un proceso comercial el rendimiento sea alrededor de 88 por ciento.

\section{LITERATURE CITED}

1. Asenjo, C. F., and Freire de Guzmán, A. R., Sci. 103 219, 1946.

2. Vieta de Ruiz, E., Durán, O., Rosenkranz, J., and Kaufmann, E., Inform. Med. 10 $160,1946$.

3. Mustard, M. J., Sci. 104 230, 1946.

4. Sanchez Nieva, F., Extraction, processing, canning, and keeping quality of acerola juice, J. Agr. Univ. P.R. 39 (4) 175-83, 1955.

5. Santini, R., Jr., J. Agr. Univ. P. R. 37 199, 1952.

6. Banga, I., and Szent-Györgyi, A., Biochem. J. 28 1625, 1935.

7. Sastri, B. N., and Sivaramakrishnan, P. R., Current Sci. $8336,1942$.

8. Mottern, H. H., and Buck, B. E., U. S. Patent 2,443,583 1948.

9. Klose, A. A., Stark, J. B., Purvis, G. G., Peat, J., and Fevold, H. L., Ind. Eng. Chem. 42 387, 1950.

10. Bessey, P. A., and King, C. G., J. Biol. Chem. 103 687, 1933. 